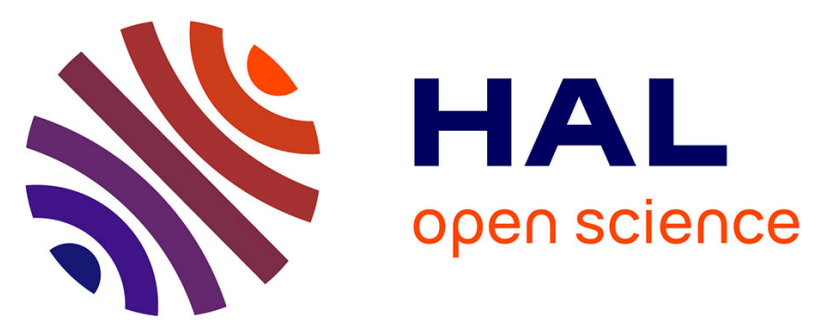

\title{
Decreased sickle red blood cell adhesion to laminin by hydroxyurea is associated with inhibition of $\mathrm{Lu} / \mathrm{BCAM}$ protein phosphorylation.
}

Pablo Bartolucci, Vicky Chaar, Julien Picot, Dora Bachir, Anoosha Habibi, Christine Fauroux, Frédéric Galactéros, Yves Colin, Caroline Le van Kim, Wassim El Nemer

\section{To cite this version:}

Pablo Bartolucci, Vicky Chaar, Julien Picot, Dora Bachir, Anoosha Habibi, et al.. Decreased sickle red blood cell adhesion to laminin by hydroxyurea is associated with inhibition of Lu/BCAM protein phosphorylation.: HU inhibits Lu/BCAM phosphorylation in sickle RBCs. Blood, 2010, 116 (12), pp.2152-9. 10.1182/blood-2009-12-257444 . inserm-00821117

\section{HAL Id: inserm-00821117 https://www.hal.inserm.fr/inserm-00821117}

Submitted on 7 May 2013

HAL is a multi-disciplinary open access archive for the deposit and dissemination of scientific research documents, whether they are published or not. The documents may come from teaching and research institutions in France or abroad, or from public or private research centers.
L'archive ouverte pluridisciplinaire HAL, est destinée au dépôt et à la diffusion de documents scientifiques de niveau recherche, publiés ou non, émanant des établissements d'enseignement et de recherche français ou étrangers, des laboratoires publics ou privés. 
Decreased sickle red blood cell adhesion to laminin by hydroxyurea is associated with inhibition of Lu/BCAM protein phosphorylation

Pablo Bartolucci, ${ }^{1,2,3,4}$ Vicky Chaar, ${ }^{1,2,3}$ Julien Picot, ${ }^{1,2,3}$ Dora Bachir, ${ }^{4}$ Anoosha Habibi, ${ }^{4}$ Christine Fauroux, ${ }^{4}$ Frédéric Galactéros, ${ }^{4}$ Yves Colin, ${ }^{1,2,3}$ Caroline Le Van Kim, ${ }^{1,2,3}$ and Wassim El Nemer ${ }^{1,2,3}$

${ }^{1}$ INSERM, UMRS 665, F-75015 Paris, France; ${ }^{2}$ Institut National de la Transfusion Sanguine, F75015 Paris, France; ${ }^{3}$ Université Paris Diderot-Paris 7, F-75013 Paris, France; ${ }^{4}$ Unité des Maladies Génétiques du Globule Rouge, Service de Médecine Interne, Hôpital Henri-Mondor, Assistance Publique-Hôpitaux de Paris, Université Paris 12, F-94010 Créteil, France

\section{Running title: HU inhibits Lu/BCAM phosphorylation in sickle RBCs}

Correspondence: Wassim El Nemer, INSERM, UMRS 665, INTS, 6, rue Alexandre Cabanel, 75015 Paris, France, E-mail: wassim.el-nemer@inserm.fr; Phone: +33 1444930 71; Fax: +33 1 43065019

Word counts: Abstract: 167; Text: 4547

Figure count: 7

Reference count: 50

Scientific category: Red cells, Iron and Erythropoiesis 


\begin{abstract}
Sickle-cell disease is characterized by painful vaso-occlusive crises during which abnormal interactions between erythroid adhesion molecules and vessel-wall proteins are thought to play a critical role. Hydroxyurea, the only drug with proven benefit in sickle-cell disease, diminishes these interactions but its mechanism of action is not fully understood. We report that, under hydroxyurea, expression of the unique erythroid laminin receptor Lu/BCAM was increased but red blood cell adhesion to laminin decreased. Because Lu/BCAM phosphorylation is known to activate cell adhesion to laminin, it was evaluated and found to be dramatically lower in hydroxyurea-treated patients. Analysis of the protein kinase A pathway showed decreased intracellular levels of the upstream effector cAMP during hydroxyurea treatment. Using a cellular model expressing recombinant Lu/BCAM, we showed that hydroxyurea led to decreased intracellular cAMP levels and diminished Lu/BCAM phosphorylation and cell adhesion. We provide evidence that hydroxyurea could reduce abnormal sickle red blood cell adhesion to the vascular wall by regulating the activation state of adhesion molecules independently of their expression level.
\end{abstract}




\section{Introduction}

Sickle-cell disease (SCD) is characterized by painful episodic vaso-occlusive crises (VOC), acute chest syndrome and a chronic inflammatory state. Hydroxyurea (HU), also called hydroxycarbamide, is the only drug now available having demonstrated benefit for SCD patients, with fewer VOC and acute chest syndromes, and lower mortality and morbidity. ${ }^{1-4}$ It was commonly thought that $\mathrm{HU}$ acted as an anti-sickling agent by increasing fetal hemoglobin ( $\mathrm{HbF})$ levels, leading to significantly less hemoglobin S polymerization. However, HU was often associated with clinical improvement before $\mathrm{HbF}$ rose significantly, suggesting that it could also act through other mechanisms. ${ }^{2}$

Growing evidence supports the hypothesis that, in SCD patients, transit of red blood cells (RBCs) into small vessels could be slowed by their abnormal adhesion to the vascular wall through interactions between erythroid adhesion molecules and proteins on the surface of endothelial cells or extracellular matrix (ECM) components. ${ }^{5-7}$ Such interactions could play a critical role in $\mathrm{HbS}$ polymerization and VOC development by prolonging $\mathrm{RBC}$ transit time in capillaries.

Several interactions have been described between SS RBCs and the endothelial vascular wall. Integrin $\alpha_{4} \beta_{1}$, expressed on young circulating reticulocytes, is one of the major actors in these interactions through its binding to vascular cell-adhesion molecule-1 (VCAM-1), fibronectin, thrombospondin (TSP) and endothelial Lu/BCAM (Lutheran/basal cell-adhesion molecule) ${ }^{8-13}$ TSP mediates adhesion of SS reticulocytes to endothelial cells by bridging CD36 molecules expressed on both cell types. ${ }^{14}$ However, the clinical severity of SCD in CD36deficient patients is not diminished. ${ }^{15}$ Landsteiner-Wiener/intercellular adhesion molecule-4 (LW/ICAM-4) and Lu/BCAM are members of the immunoglobulin superfamily, expressed on young and mature RBCs; they are also involved in the abnormal adhesion of SS RBCs through 
interactions with endothelial integrin $\alpha_{v} \beta_{3}$ and ECM laminin 511/521, respectively. ${ }^{16-21}$ In vivo, HU decreases the percentage of circulating CD36- and $\alpha 4 \beta 1$-expressing reticulocytes ${ }^{22}$ and CD36 and $\alpha_{4} \beta_{1}$ expression levels at the mRNA and protein levels; ${ }^{23}$ it also reduces phosphatidylserine expression on the surfaces of erythrocytes and platelets, ${ }^{24}$ and plasma levels of soluble VCAM-1 and endothelin- $1 .{ }^{25,26} \mathrm{HU}$ diminishes SS RBC adhesion to endothelial cells and the ECM proteins, fibronectin, TSP and laminin. ${ }^{23,27,28}$ These decreases are consistent with less CD36, $\alpha_{4} \beta_{1}$ and LW/ICAM-4 expression on the surfaces of SS reticulocytes and erythrocytes. ${ }^{29}$

Surprisingly, Odièvre et al showed that RBC expression of Lu/BCAM, the unique erythroid receptor for laminin, ${ }^{19,21}$ was significantly elevated in HU-treated children. ${ }^{29}$ Consequently, SS RBC adhesion to laminin could not be directly linked to the cell-surface $\mathrm{Lu} / \mathrm{BCAM}$ expression level. $\mathrm{Lu} / \mathrm{BCAM}$ is responsible for abnormal SS RBC adhesion to laminin in a protein-kinase A (PKA)- and/or Rap1-dependent manner. ${ }^{30,31}$ Although Lu/BCAM is expressed on normal (AA) and SS RBCs, only SS RBCs adhere to laminin and resist high shearstress forces. ${ }^{19,21,32}$ This adhesion is activated by the phosphorylation of serine 621 in the Lu/BCAM cytoplasmic domain upon PKA-pathway activation. ${ }^{33} \mathrm{Lu} / \mathrm{BCAM}$ is not phosphorylated in AA RBCs. ${ }^{33}$

For this study, we hypothesized that HU could interfere with SS RBC adhesion to laminin by modulating Lu/BCAM phosphorylation. Adhesion to laminin of RBCs from adult SCD patients, HU-treated or not, was investigated during a quiescent phase of the disease (steadystate). $\mathrm{HU}$ increased Lu/BCAM erythroid expression but decreased RBC adhesion to laminin; that diminished adhesion was correlated with less Lu/BCAM phosphorylation. Analysis of the signaling pathways involved in Lu/BCAM phosphorylation showed decreased intracellular levels of cAMP, the upstream effector of both PKA and Epac/Rap1 pathways, during HU treatment. These observations were then confirmed in a cellular model expressing recombinant Lu/BCAM 
long isoform $\mathrm{Lu}$. Our results provide the first evidence that $\mathrm{HU}$ could reduce abnormal RBC adhesion to the vascular wall by acting on the activation state of adhesion molecules, eg $\mathrm{Lu} / \mathrm{BCAM}$, independently of their expression level. 


\section{Patients and Methods}

\section{Patients and blood samples}

Homozygous SCD patients (SS) at least 18 years old, able to give their informed consent and consulting at our Adult Sickle-Cell Referral Center were eligible for inclusion in this study, which was approved by the local ethics committee (Comité de Protection des Personnes) and was conducted in accordance with the provisions of the Declaration of Helsinki, and local laws and regulations. Experiments were performed with freshly drawn EDTA-anticoagulated venous blood from healthy adult donors or HU-treated or untreated adult SS patients. SCD steady-state was defined as a visit at least $\geq 1$ months after an acute clinical event and $\geq 3$ months after blood transfusion. None of the included patients had an acute SCD-related event during the 2 weeks following sampling at steady-state.

\section{Cell lines and antibodies}

Human erythroleukemic K562 cells expressing the long human Lu/BCAM isoform (Lu gp), K562-Lu, were obtained and grown, in the absence or presence of $250 \mu \mathrm{M} \mathrm{HU}$ (Sigma-Aldrich, Saint-Quentin Fallavier, France) for 24 and 48 hours, ${ }^{27}$ as described. ${ }^{19}$ Mouse anti-human Lu/BCAM monoclonal antibody (mAb), clone F241, was produced in our institute. ${ }^{33}$ Biotinylated goat polyclonal anti-Lu/BCAM antibody was from R\&D Systems (Minneapolis, MN).

\section{Flow cytometry}

Percentages of reticulocytes in whole or fractionated blood samples were determined using thiazole orange dye (Retic-Count ${ }^{\mathrm{TM}}$, Becton-Dickinson, San Jose, CA) and a BD FACScanto II flow cytometer (Becton-Dickinson) with FACSDiva software (v6.1.2) for acquisition and analysis. The percentage was determined by gating the red cell population based on size (forward 
scatter) and granularity (side scatter). Expression of cell-surface Lu/BCAM on RBCs and transfected K562-Lu cells was evaluated with anti-Lu/BCAM F241 mAb. Mean fluorescence intensity (MFI) was determined under the same conditions for all samples. Lu/BCAM antigen strength varies widely among individuals and exhibits heterogeneity between individual RBCs within a given individual. This variability accounts for the mixed field-agglutination patterns showing clumps of agglutinated cells in the presence of many free cells, usually seen with Lutheran antisera especially anti-Lu ${ }^{\mathrm{a}}$, and the wide range of survival times of $\mathrm{Lu}(\mathrm{b}+)$ cells introduced into a Lu(a+b-) person with anti-Lu ${ }^{\mathrm{b}}{ }^{34}$ Therefore, Lu/BCAM-positive RBCs were gated and Lu/BCAM MFI was calculated only for this population.

\section{Percoll double-density separation}

All collected blood samples designated for this fractionation were kept at $4{ }^{\circ} \mathrm{C}$ overnight, then subjected to density separation at room temperature as described. ${ }^{35}$ Percoll (Sigma-Aldrich) was diluted in $125 \mathrm{mM} \mathrm{NaCl}, 4.5 \mathrm{mM} \mathrm{KCl}, 3 \%$ bovine serum albumin (BSA) to obtain densities of 1.076 and $1.085 ; 3 \mathrm{ml}$ of the latter density were placed in an empty $15-\mathrm{ml}$ polypropylene tube followed by $3 \mathrm{ml}$ of the former, then $3 \mathrm{ml}$ of whole blood were carefully loaded onto the surface. After centrifugation (30 min, 1000×g), blood fractions were collected and washed 3 times with Hanks' buffer (Sigma-Aldrich). An aliquot was saved to count reticulocytes by flow cytometry and the rest was used in adhesion and phosphorylation assays.

\section{Adhesion assays}

$\mathrm{RBC}$ and $\mathrm{K} 562-\mathrm{Lu}-\mathrm{cell}$ adhesions to laminin were measured under physiological flow conditions using a plate flow chamber, by a person blinded to the patient's status, as described. ${ }^{33}$ Laminin 511/521 (10 $\mu \mathrm{g}$, Sigma-Aldrich) from human placenta was immobilized in uncoated $\mu \mathrm{I}$ 
microslides (ibidi, Munich, Germany) (internal channel dimensions: length $50 \mathrm{~mm}$, width $5 \mathrm{~mm}$, height $0.4 \mathrm{~mm}$ ) at $4^{\circ} \mathrm{C}$ overnight. RBCs and $\mathrm{K} 562-\mathrm{Lu}$ cells were washed and suspended, respectively, in Hanks' buffer supplemented with $0.2 \%$ BSA at hematocrit $0.5 \%$ and $10^{7}$ cells $/ \mathrm{ml}$. Cells were perfused through the microslide at a shear stress of $0.4 \mathrm{dyne} / \mathrm{cm}^{2}$ for $5 \mathrm{~min}$ at $37^{\circ} \mathrm{C}$ and washouts used Hanks' buffer at 0.4 and 2 dyne $/ \mathrm{cm}^{2}$ for 5 min each. After each wash, adherent cells were counted in 5 representative areas along the centerline of the microslide by microscopy using Optimas 6.1 image analysis system (Media Cybernetics, Silver Spring, MD).

\section{Phosphorylation assays}

RBCs and K562-Lu cells were phospholabeled as described. ${ }^{33}$ Briefly, RBCs (200 $\left.\mu 1\right)$ were incubated in $1.8 \mathrm{ml}$ of buffer A $(150 \mathrm{mM} \mathrm{NaCl} ; 20 \mathrm{mM}$ Tris- $\mathrm{HCl}, \mathrm{pH} 7.5 ; 10 \mathrm{mM} \mathrm{KCl} ; 1 \mathrm{mM}$ $\mathrm{MgCl}_{2}$ ) for 4 hours at $35^{\circ} \mathrm{C}$; centrifuged at $750 \times g$ for 3 min and suspended in $1.8 \mathrm{ml}$ of buffer A

containing ${ }^{32} \mathrm{P}(300 \mu \mathrm{Ci})$ for 14 hours at $35^{\circ} \mathrm{C}$. RBCs were washed twice with cold PBS and lysed with buffer A containing 1\% Triton X-100, 0.2\% BSA, phosphatase (Sigma-Aldrich) and protease inhibitor cocktails (Roche, Basel, Switzerland). Lu/BCAM was immunoprecipitated with F241 mAb and protein A-Sepharose CL4B beads (Roche) overnight at $4{ }^{\circ} \mathrm{C}$. After SDS-PAGE and protein transfer, phosphorylated proteins were detected and quantified $(\mathrm{P})$ with a FujiFilm BAS-1800 II PhosphorImager, using Image Reader BAS-1800 II V1.8 and Multi Gauge v3.0 software, respectively (Fuji, Tokyo, Japan). Total Lu/BCAM was then revealed on the same membrane by Western blotting using biotinylated anti-Lu/BCAM antibody (R\&D Systems) and the Molecular Imager Gel Doc XR System (Bio-Rad, Marnes-la-Coquette, France). Proteins were quantified (WB) using Quantity One software (Bio-Rad). The P/WB ratio was calculated to determine the proportion of phosphorylated Lu/BCAM among total immunoprecipitated Lu/BCAM proteins. 


\section{Cyclic AMP quantification}

Total cAMP was measured in RBCs and K562-Lu cells as described in the Cayman Chemical (Ann Arbor, MI) cAMP enzyme-immunoassay kit. Briefly, $70 \mu 1$ of RBCs or $5 \times 10^{6}$ K562-Lu cells were lysed in $430 \mu \mathrm{l}$ or $200 \mu \mathrm{l}$ of $0.1 \mathrm{M} \mathrm{HCl}$, respectively. After centrifugation, supernatants were acetylated and $50 \mu 1$ of each were added per well in a 96-well ELISA plate provided in the kit. After an 18-hour incubation at $4^{\circ} \mathrm{C}$, wells were washed and $200 \mu$ l of revelation buffer were added to each well. After 2 hours of incubation at room temperature, total cAMP levels were measured according to the manufacturer's instructions.

\section{Statistical analyses}

Results are expressed as medians [interquartile range (IQR)], means $\pm \mathrm{SD}$, means \pm s.e.m., numbers or percentages, as appropriate. Nonparametric tests were used because normal distribution could not be assumed because of the small samples $(<30)$ and those data had skewed distributions. Thus, quantitative parameters were compared between groups using a MannWhitney test, Kruskal-Wallis test for $>2$ groups, Wilcoxon signed-rank test for paired observations, or Friedman test for repeated measures. Fisher's exact test was used for variance comparisons. Correlations were sought with simple linear regression and Pearson's correlation. $P$ $\leq .05$ was considered significant. 


\section{Results}

\section{Patients}

The 49 homozygous SCD patients enrolled in this study formed 3 groups: 13 patients followed prospectively before and after starting HU (20 mg/kg/d), with 6 months of follow-up (pre-post group); 15 untreated patients (UT group); and 21 HU-treated patients (HU group). Results obtained with blood samples from the pre-post group before and > 6 months after starting HU were also included in the UT and HU groups, thereby raising the respective numbers of blood samples to 28 and 34 . The mean \pm SD age and the male/female ratio were $36 \pm 8.34$ years and 0.75 for the UT group and $32 \pm 8.64$ years and 0.41 for the HU group. RBCs from 7 healthy donors were also analyzed.

\section{Less adhesion to laminin by SS RBCs from HU-treated patients}

The effect of HU treatment on SS RBC adhesion to laminin was investigated with adhesion assays under flow conditions with 34 blood samples from HU-treated patients and 28 from UT patients. HU-exposed SS RBCs adhered less than UT SS RBCs with respective medians of 40 vs 200 $\mathrm{RBCs} / \mathrm{mm}^{2}$ at $2 \mathrm{dyne} / \mathrm{cm}^{2}(P=.007)($ Figure $1 \mathrm{~A})$ and $160 \mathrm{vs} 550 \mathrm{RBCs} / \mathrm{mm}^{2}$ at $0.4 \mathrm{dyne} / \mathrm{cm}^{2}(P=$ .008) (not shown). The impact of HU on cell adhesion was also analyzed by comparing the UT and $\mathrm{HU}$ groups in terms of RBC-adhesion value distributions. We found that the dispersion of values was much wider for the UT group than the HU group, with significantly different betweengroup variance values (Fisher's exact test, $P<.0001$ ). Adhesion of RBCs from 7 control donors was close to null and significantly lower than for the UT and HU groups $(P<.01)$.

Because of wide interindividual variability in SCD, the same assays were run using blood samples from 13 pre-post group patients which showed that adhesion was significantly lower 
after 6 months of $\mathrm{HU}(P=.013)$, and dramatically diminished for the 5 patients with the highest adhesion levels before starting HU (Figure 1B).

\section{SS RBC adhesion to laminin is not correlated with the $\mathrm{Lu} / \mathrm{BCAM}$ expression level}

To determine whether SS RBC adhesion to laminin was conditioned by the Lu/BCAM expression level, flow cytometry and cell-adhesion assays were conducted with 14 and 12 HU- and UT-group blood samples, respectively. When all patients were taken into account, no correlation was found between the adhesion level and Lu/BCAM expression, as determined by the percentage of RBCs expressing $\mathrm{Lu} / \mathrm{BCAM}$ or the number of Lu/BCAM molecules/RBC, estimated by Lu/BCAMpositive RBC MFI (Figure 2A,B). When UT and HU-treated patients were considered separately, no correlation was found between adhesion level and Lu/BCAM expression, although a trend emerged for the UT group associating the adhesion level and MFI of Lu/BCAM-positive RBCs ( $P$ $\left.=.06, r^{2}=.3, \mathrm{n}=12\right)$.

Paradoxically, and as previously reported by Odièvre et al, ${ }^{29}$ flow cytometry analysis of blood samples from $19 \mathrm{HU}$-group and 19 UT-group patients showed that the percentage of Lu/BCAM-expressing cells and the number of Lu/BCAM molecules/RBC were significantly higher for the HU group than the UT group $(P<.0001)$ (Figure $2 \mathrm{C}, \mathrm{D})$; this result was also confirmed for 5 other pre-post group patients who had significantly increased Lu/BCAM expression under HU (Figure 2E,F).

Two Lu/BCAM glycoprotein (gp) isoforms are present on human RBCs, Lu (85 kDa) and $\mathrm{Lu}(\mathrm{v} 13)(78 \mathrm{kDa})$; they result from the alternative splicing of intron 13 and differ by the lengths of their cytoplasmic domains. ${ }^{36,37}$ Because Lu/BCAM antigens reside on both isoforms, flow cytometry analysis could not show whether one or both of Lu/BCAM isoforms were overexpressed under HU. Therefore, Lu/BCAM gp were immunoprecipitated from SS RBCs of 5 
pre-post group patients and revealed by Western blotting (Figure 3A, typical result). After protein quantification, the $\mathrm{Lu} / \mathrm{Lu}(\mathrm{v} 13)$ ratio was determined for the 5 patients at all treatment stages (Figure 3B). It showed that Lu was predominantly expressed and that HU did not alter the $\mathrm{Lu} / \mathrm{Lu}(\mathrm{v} 13)$ ratio. This finding indicated that $\mathrm{Lu} / \mathrm{BCAM}$ overexpression under HU was due to an overexpression of both isoforms, suggesting that HU could up-regulate $L U$ gene expression in erythroid cells. In addition, it showed that HU does not modulate the alternative splicing generating $\mathrm{Lu}$ and $\mathrm{Lu}(\mathrm{v} 13)$.

\section{Decreased Lu/BCAM phosphorylation on RBCs under HU}

We postulated that HU might reduce SS RBC adhesion by inhibiting Lu/BCAM activation. Lu, but not Lu(v13), is phosphorylated on SS RBCs in a PKA-dependent manner. ${ }^{33}$ To determine whether HU could modulate phosphorylation of the Lu isoform, radiophospholabeling experiments were performed with RBCs from the pre-post group to assess Lu phosphorylation status in the same individual before and during HU treatment. SS RBC samples were obtained from 5 patients before starting $\mathrm{HU}$ and at regular intervals during treatment: 15 days, 2, 4 and $>6$ months after starting HU. After RBC radiophospholabeling, Lu/BCAM was immunoprecipitated with F241 mAb, which recognizes the extracellular domain of both isoforms. Phosphorylated (P) Lu gp was quantified by phosphorImager after SDS-PAGE and protein transfer to a nitrocellulose membrane. Total amounts of immunoprecipitated Lu gp were then quantified on the same membrane by Western blotting (WB). The Lu-gp phosphorylated fraction was estimated by calculating the P/WB ratio of those determinations (Figure 4A, typical result). As expected, both isoforms were expressed on RBCs but only Lu gp was phosphorylated (Figure 4A). It is noteworthy that Lu phosphorylation decreased during HU treatment in this patient while no significant drop was observed for his percentage of circulating reticulocytes (Figure 4A). 
Decreased Lu-gp phosphorylation was observed after 15 days of HU for 3 patients and within 2 months for the 2 others. This reduction persisted throughout the 6 months of follow-up and was highly significant after 6 months of treatment $(P=.005, \mathrm{n}=5$ patients) (Figure 4B,C). Less phosphorylation was associated with reduced RBC adhesion to laminin (Figure 4D). A linear regression analysis showed a partial correlation between RBC adhesion and Lu/BCAM phosphorylation (Figure 4E, $P=.0005, r^{2}=0.496$ ). Three other parameters known to be modulated by $\mathrm{HU}$ were measured. As expected, the percentage of reticulocytes decreased during $\mathrm{HU}$ treatment (Figure 4F), while the $\mathrm{Hb}$ concentration and the percentage of $\mathrm{HbF}$ increased (Figure 4G,H).

\section{More adhesion to laminin of reticulocytes where Lu/BCAM phosphorylation mainly occurs}

The SCD RBC lifespan is dramatically shortened and the corresponding reticulocyte count is much higher than in healthy controls. To determine whether the SS reticulocyte percentage could influence RBC adhesion to laminin, flow-adhesion assays were performed with reticulocyteenriched UT RBCs obtained after whole blood fractionation by Percoll double-density gradient centrifugation. The median percentage of reticulocytes in whole blood (W), the low-density reticulocyte-rich fraction (LDF) and the pellet (reticulocyte-poor fraction, PF) were 8.2, 53 and 4.8, respectively. The LDF exhibited the highest cell-adhesion level, adhering more than cells from whole blood $(P<.01)$ and the pellet $(P<.05)$ (Figure 5A). Because Lu/BCAM-mediated cell adhesion to laminin is modulated by phosphorylation, we analyzed Lu-isoform phosphorylation in both fractions and whole blood (Figure 5B). The phosphorylation level (P/WB ratio) was directly correlated to the percentage of reticulocytes (Figure $5 \mathrm{C}, P<.0001, r^{2}=0.985$, $\mathrm{n}=5$ patients), indicating that Lu-gp was phosphorylated mainly in young immature RBCs of UT patients. 
Considering these results we asked the question whether the decreased Lu/BCAM phosphorylation in HU-treated patients could be a consequence of the HU-driven decrease of circulating reticulocytes. To answer this question Lu/BCAM phosphorylation levels were determined in RBCs from 8 HU-treated patients and plotted against their percentage of reticulocytes (Figure 5D). As expected, low levels of Lu/BCAM phosphorylation were obtained for all patients. Interestingly, higher reticulocyte count was not associated with higher Lu/BCAM phosphorylation. Figure 5D shows that Lu/BCAM phosphorylation was independent of the reticulocyte percentage of HU-treated patients indicating that the decrease of Lu/BCAM phosphorylation in HU-treated patients was not a consequence of their decreased reticulocyte count.

\section{HU exposure leads to less K562-Lu cell adhesion to laminin and less Lu-gp phosphorylation}

In an attempt to test the effect of HU on SS RBCs in vitro, RBCs were incubated with or without $\mathrm{HU}$ for 24 and 48 hours at $37^{\circ} \mathrm{C}$ but, unfortunately, severe hemolysis ensued, even in the absence of HU. Therefore, SS RBCs were replaced by a transfected erythroleukemic cell line expressing recombinant Lu gp, K562-Lu cells. Adhesion and phospholabeling assays were run before and after incubating these cells with HU for 24 and 48 hours. Because HU is cytotoxic, cell viability was monitored by the cell-growth curve and flow cytometry using TO-PRO3 iodide. Cell proliferation was slowed down by HU and cell death was mildly but not sharply induced, as only $2.4 \%$ and $4.7 \%$ dead cells were detected at 24 and 48 hours, respectively $(n=3)$. Adhesion at 24 hours was comparable to untreated cells. K562-Lu cell adhesion to laminin was 12 -fold lower at 48 hours than untreated control cells (Figure 6A). This difference was not due to inhibition of Lugp expression, as determined by flow cytometry (data not shown). The lower cell adhesion was associated with markedly less Lu-gp phosphorylation of HU-treated cells at 48 hours (Figure 6B), 
confirming the relationship between the Lu-gp-phosphorylation level and cell adhesion, and showing that HU could diminish cell adhesion to laminin by modulating Lu-gp phosphorylation.

\section{Intracellular levels of cAMP are decreased under HU treatment}

Two signaling pathways involved in enhanced Lu/BCAM-mediated SS RBC adhesion to laminin have been described: the PKA ${ }^{30,33}$ and the Epac/Rap $1^{31}$ pathways. Because cAMP is a common upstream effector of both pathways, its intracellular levels were measured in SS RBCs. We first compared the basal levels of cAMP in SS versus AA RBCs and found higher levels in the former, as previously reported ${ }^{30}$ (Figure 7A). We then wondered whether cAMP production could be modulated under HU treatment. Intracellular levels of cAMP were determined in RBC samples of 7 pre-post group patients and showed a steady and significant decrease over time (Figure 7B, $P=$ .002). The effect of HU on intracellular cAMP levels was also measured using K562-Lu cells treated for 24 and 48 hours and yielded similar results (Figure 7C). These findings indicated that the lower Lu/BCAM phosphorylation under $\mathrm{HU}$ could be a direct consequence of a diminished stimulation of PKA and/or Epac/Rap1 pathways. 


\section{Discussion}

The pathophysiology of SCD is complex and not fully understood. The first step in the sickling process is $\mathrm{HbS}$ polymerization; hence, factors delaying reoxygenation of the $\mathrm{HbS}$ deoxygenated form or increasing the intracellular $\mathrm{HbS}$ concentration are thought to play major roles in initiating and accelerating the sickling process, consequently promoting the blockade of the microcirculation. ${ }^{38} \mathrm{RBC}$ adhesion to the vascular wall probably favors the formation of $\mathrm{HbS}$ polymers by slowing the flow of cells circulating through capillaries, thereby leading to the next step, which is vaso-occlusion. Many observations support an important role of abnormal cell adhesion in the obstruction of microvessels or in facilitating the trapping of sickle cells in postcapillary venules. ${ }^{5-7}$ We focused our study on Lu/BCAM, as they are the unique erythroid receptors of laminin, a major ECM protein, and are expressed in young and mature RBCs, unlike CD36 and integrin $\alpha_{4} \beta_{1}$, which are restricted to reticulocytes. Considering the important interindividual heterogeneity in SCD and the variability of RBC characteristics during VOC, ${ }^{39}$ we applied strict patient inclusion criteria to minimize potential biases (see Patients and Methods).

Hillery et al provided the first evidence that HU decreased SS RBC adhesion to TSP and laminin, but too few patients were studied to draw conclusions regarding potential correlations between RBC adhesion and the clinical response. ${ }^{28}$ Because HU modulates the expression of

several genes, up-regulating $\mathrm{HbF}$ and down-regulating adhesion molecules CD36 and $\alpha_{4} \beta_{1},{ }^{22,23,29}$ it could be expected that less adhesion to laminin resulted from less Lu/BCAM. Paradoxically, Odièvre et al's findings did not support that hypothesis, as they showed that HU enhanced erythroid Lu/BCAM expression in children. ${ }^{29}$ Thus, SS RBC adhesion to laminin does not reflect the $\mathrm{Lu} / \mathrm{BCAM}$-expression level on the cell surface.

Herein, we confirmed that $\mathrm{HU}$ significantly increased erythroid Lu/BCAM expression by enhancing both the percentage of $\mathrm{Lu} / \mathrm{BCAM}$-positive $\mathrm{RBCs}$ and the numbers of $\mathrm{Lu} / \mathrm{BCAM}$ 
copies/RBC. We showed that $\mathrm{HU}$ did not modulate the alternative splicing generating $\mathrm{Lu}$ and $\mathrm{Lu}(\mathrm{v} 13)$ isoforms but rather up-regulated erythroid expression of the $L U$ gene. As expected, $\mathrm{HU}$ increased the $\mathrm{Hb}$ concentration and $\mathrm{HbF}$ percentage. Pertinently, the lower cell adhesion and $\mathrm{Lu} / \mathrm{BCAM}$ phosphorylation preceded the $\mathrm{HbF}$ rise. Moreover, we showed that the reduced $\mathrm{RBC}$ adhesion to laminin under HU was associated with dramatically decreased Lu/BCAM longisoform phosphorylation, despite its enhanced expression, clearly demonstrated for the pre-postgroup patients. This decreased phosphorylation was most probably a direct consequence of the diminished intracellular cAMP levels measured in these patients during HU treatment. Thus, HU could modulate PKA and/or Epac/Rap1 pathways, downstream of cAMP, and inhibit Lu/BCAM phosphorylation. As intracellular cAMP levels are controlled by several effectors including adenylyl cyclase and phosphodiesterases, further studies are needed to fully characterize the HU mechanism of action in SCD. Our finding agrees with the results of other studies describing the role of $\mathrm{HU}$ in regulating cellular functions via signaling pathways. Some observations suggested that HU might raise nitric oxide levels by stimulating vascular endothelial cell production of it via the eNOS-cGMP pathway. ${ }^{40-43} \mathrm{HU}$ could also prevent neutrophil activation and adhesion to fibronectin in a cAMP-PKA-dependent manner. ${ }^{44,45}$ The in vivo effect of $\mathrm{HU}$ on Lu/BCAM longisoform phosphorylation and cAMP decrease could not be tested ex vivo using SS RBCs because of hemolysis. Nevertheless, using human erythroleukemic K562-Lu cells expressing recombinant Lu gp, we showed that the ex vivo effects of HU were similar to those observed for SS RBCs from HU-treated SCD patients. Although the K562 cell line derives from an erythroid lineage it could not be compared to RBCs. Nevertheless, these experiments revealed that HU could negatively impact cAMP levels, Lu/BCAM phosphorylation and cell adhesion to laminin in this cell line suggesting that it could help deciphering the HU mechanism of action. 
Another new finding was the correlation between Lu-gp phosphorylation and the percentage of reticulocytes in UT patients, which could explain why their reticulocyte-enriched fractions adhered more to laminin than mature RBCs. Two studies investigated SS RBC adhesion to laminin according to their density and reported that cells from the dense fraction were the most adherent. ${ }^{46,47}$ Our results were obtained using a different experimental approach to have reticulocyte-enriched fractions. The 5-10\% of very dense and irreversibly sickled cells, reported to be the most adherent, ${ }^{46,47}$ were diluted in our pellet fraction with cells of intermediate density known to be much less adherent. We chose to focus on reticulocytes, because no Lu/BCAM phosphorylation was detected in mature dense RBCs and our objective was to determine the effect of $\mathrm{HU}$ on Lu/BCAM activation through the phosphorylation of the long Lu isoform. Our results showed that, contrary to what was observed for UT patients, the Lu/BCAM phosphorylation level was independent of the reticulocyte count in HU-treated patients, as patients with $<3 \%$ and $>7 \%$ of reticulocytes showed similar phosphorylation levels (Figure 5D). We showed that the HU effect on RBC adhesion preceded the reticulocyte count decline. Pre-post group RBC adhesion to laminin was often diminished before the reticulocyte count changed significantly, revealing a qualitative modification of the adhesive properties of circulating reticulocytes. This was clearly demonstrated for the patient in figure 4A who showed a dramatic decrease of Lu/BCAM phosphorylation after $>6$ months of HU therapy while no significant change was observed for his percentage of circulating reticulocytes. In addition, the reticulocyte-count diminution under HU in the 5 pre-post group patients was not statistically significant $(P=.26)$. Nevertheless, because the phosphorylation level results from the balance between kinase and phosphatase activities, and the RBC stock of kinases declines with age, it cannot be excluded that the prolongation of RBC survival under HU could partially contribute to the reduced Lu/BCAM phosphorylation. 
In addition to phosphorylation, Lu/BCAM-mediated cell adhesion to laminin is regulated by the interaction of the Lu/BCAM cytoplasmic domain with the spectrin-based skeleton. ${ }^{48-50}$ Loss of interaction with spectrin increases Lu/BCAM-mediated cell adhesion to laminin. ${ }^{48,49}$ Since $\mathrm{HbS}$ polymerization during sickling generates skeleton disorganization, it could negatively affect the Lu/BCAM-spectrin interaction, of both $\mathrm{Lu}$ and $\mathrm{Lu}(\mathrm{v} 13)$ isoforms, and lead to enhanced adhesion of sickled RBCs, independently of phosphorylation events. This scenario could account for the partial correlation between phosphorylation and adhesion in our experiments $\left(r^{2}=0.496\right)$ and for the previously reported high adhesion of very dense, irreversibly sickled cells. ${ }^{46,47}$ Several RBC skeletal proteins undergo phosphorylation, which regulates their interactions with other cytoplasmic proteins. Our results showed an HU impact on phosphorylation events in RBCs and, thus, it could modulate protein-protein interactions. Further studies are needed to investigate the role of the Lu/BCAM-spectrin interaction in SS RBC adhesion to laminin and the effect of HU on it.

Altogether, our results strongly suggest a critical role for HU in inhibiting Lu-gp phosphorylation, which was associated with significantly less SS RBC adhesion to laminin. It is widely accepted that HU reduces SS RBC adhesion by down-regulating the reticulocyte count and the expression levels of adhesion molecules. Our findings show, for the first time, that HU could also play a role in reducing receptor-ligand interactions, most probably by modulating their affinity, which could explain the very short duration of HU pharmacological activity, independent of its reconditioned $\mathrm{RBC}$ renewal wave.

In conclusion, the results of our study reveal a new $\mathrm{HU}$ mechanism of action in regulating SS RBC adhesion by modulating the phosphorylation state of an adhesion molecule independently of its expression level. Future investigations should help characterize the pathway leading to this HU-induced modulation, which could give rise to new therapeutic perspectives. 


\section{Acknowledgments}

The authors would like to thank the Centre National de Référence sur les Groupes Sanguins for the storage and management of blood samples. The investigation was supported by the Institut National de la Transfusion Sanguine (INTS), the Institut National de la Santé et de la Recherche Médicale (INSERM), a grant from the Agence Nationale de la Recherche (ANR, SCADHESION 2007), a grant from Région Île-de-France (SESAME 2007 no. F-08-1104/R) and a fellowship "maladies rares" from the Société Française de Médecine Interne (SNFMI) and Actélion. 


\section{Authorship}

Contribution: P.B. designed and performed research, analyzed data and wrote the paper. V.C. designed and ran experiments and commented on the manuscript. J.P. designed and performed cytometry experiments and commented on the manuscript. D.B., A.H., C.F. and F.G. collected blood samples and provided patients' clinical data. Y.C. and C.L.V.K. discussed the results, gave advice and commented on the manuscript at all stages. W.E.N. supervised the project, designed and performed research and wrote the paper.

Conflict of interest: The authors have no conflict of interest to declare. 


\section{References}

1. Brawley OW, Cornelius LJ, Edwards LR, et al. National Institutes of Health Consensus Development Conference statement: hydroxyurea treatment for sickle cell disease. Ann Intern Med 2008;148(12):932-938.

2. Charache S, Terrin ML, Moore RD, et al. Effect of hydroxyurea on the frequency of painful crises in sickle cell anemia. Investigators of the Multicenter Study of Hydroxyurea in Sickle Cell Anemia. N Engl J Med 1995;332(20):1317-1322.

3. Steinberg MH, Barton F, Castro O, et al. Effect of hydroxyurea on mortality and morbidity in adult sickle cell anemia: risks and benefits up to 9 years of treatment. JAMA 2003;289(13):1645-1651.

4. Lanzkron S, Strouse JJ, Wilson R, et al. Systematic review: Hydroxyurea for the treatment of adults with sickle cell disease. Ann Intern Med 2008;148(12):939-955.

5. Frenette PS. Sickle cell vaso-occlusion: multistep and multicellular paradigm. Curr Opin Hematol 2002;9(2):101-106.

6. Hebbel RP, Osarogiagbon R, Kaul D. The endothelial biology of sickle cell disease: inflammation and a chronic vasculopathy. Microcirculation 2004;11(2):129-151.

7. Telen MJ. Erythrocyte adhesion receptors: blood group antigens and related molecules. Transfus Med Rev 2005;19(1):32-44.

8. Brittain JE, Han J, Ataga KI, Orringer EP, Parise LV. Mechanism of CD47-induced alpha4beta1 integrin activation and adhesion in sickle reticulocytes. $J$ Biol Chem 2004;279(41):42393-42402.

9. Joneckis CC, Ackley RL, Orringer EP, Wayner EA, Parise LV. Integrin alpha 4 beta 1 and glycoprotein IV (CD36) are expressed on circulating reticulocytes in sickle cell anemia. Blood 1993;82(12):3548-3555.

10. Kumar A, Eckmam JR, Swerlick RA, Wick TM. Phorbol ester stimulation increases sickle erythrocyte adherence to endothelium: a novel pathway involving alpha 4 beta 1 integrin receptors on sickle reticulocytes and fibronectin. Blood 1996;88(11):4348-4358.

11. Parise LV, Telen MJ. Erythrocyte adhesion in sickle cell disease. Curr Hematol Rep 2003;2(2):102-108.

12. Swerlick RA, Eckman JR, Kumar A, Jeitler M, Wick TM. Alpha 4 beta 1-integrin expression on sickle reticulocytes: vascular cell adhesion molecule-1-dependent binding to endothelium. Blood 1993;82(6):1891-1899.

13. El Nemer W, Wautier MP, Rahuel C, et al. Endothelial Lu/BCAM glycoproteins are novel ligands for red blood cell alpha4beta1 integrin: role in adhesion of sickle red blood cells to endothelial cells. Blood 2007;109(8):3544-3551.

14. Sugihara K, Sugihara T, Mohandas N, Hebbel RP. Thrombospondin mediates adherence of CD36+ sickle reticulocytes to endothelial cells. Blood 1992;80(10):2634-2642.

15. Lee K, Gane P, Roudot-Thoraval F, et al. The nonexpression of CD36 on reticulocytes and mature red blood cells does not modify the clinical course of patients with sickle cell anemia.

Blood 2001;98(4):966-971.

16. Hermand P, Gane P, Callebaut I, Kieffer N, Cartron JP, Bailly P. Integrin receptor specificity for human red cell ICAM-4 ligand. Critical residues for alphaIIbeta3 binding. Eur J Biochem 2004;271(18):3729-3740.

17. Kaul DK, Liu XD, Zhang X, et al. Peptides based on alphaV-binding domains of erythrocyte ICAM-4 inhibit sickle red cell-endothelial interactions and vaso-occlusion in the microcirculation. Am J Physiol Cell Physiol 2006;291(5):C922-930. 
18. Mankelow TJ, Spring FA, Parsons SF, et al. Identification of critical amino-acid residues on the erythroid intercellular adhesion molecule-4 (ICAM-4) mediating adhesion to alpha V integrins. Blood 2004;103(4):1503-1508.

19. El Nemer W, Gane P, Colin Y, et al. The Lutheran blood group glycoproteins, the erythroid receptors for laminin, are adhesion molecules. J Biol Chem 1998;273(27):16686-16693.

20. El Nemer W, Gane P, Colin Y, et al. Characterization of the laminin binding domains of the Lutheran blood group glycoprotein. J Biol Chem 2001;276(26):23757-23762.

21. Udani M, Zen Q, Cottman M, et al. Basal cell adhesion molecule/lutheran protein. The receptor critical for sickle cell adhesion to laminin. J Clin Invest 1998;101(11):2550-2558.

22. Styles LA, Lubin B, Vichinsky E, et al. Decrease of very late activation antigen-4 and CD36 on reticulocytes in sickle cell patients treated with hydroxyurea. Blood 1997;89(7):25542559.

23. Gambero S, Canalli AA, Traina F, et al. Therapy with hydroxyurea is associated with reduced adhesion molecule gene and protein expression in sickle red cells with a concomitant reduction in adhesive properties. Eur J Haematol 2007;78(2):144-151.

24. Covas DT, de Lucena Angulo I, Vianna Bonini Palma P, Zago MA. Effects of hydroxyurea on the membrane of erythrocytes and platelets in sickle cell anemia. Haematologica 2004;89(3):273-280.

25. Lapoumeroulie C, Benkerrou M, Odievre MH, Ducrocq R, Brun M, Elion J. Decreased plasma endothelin-1 levels in children with sickle cell disease treated with hydroxyurea. Haematologica 2005;90(3):401-403.

26. Saleh AW, Hillen HF, Duits AJ. Levels of endothelial, neutrophil and platelet-specific factors in sickle cell anemia patients during hydroxyurea therapy. Acta Haematol 1999;102(1):3137.

27. Brun M, Bourdoulous S, Couraud PO, Elion J, Krishnamoorthy R, Lapoumeroulie C. Hydroxyurea downregulates endothelin-1 gene expression and upregulates ICAM-1 gene expression in cultured human endothelial cells. Pharmacogenomics J 2003;3(4):215-226.

28. Hillery CA, Du MC, Wang WC, Scott JP. Hydroxyurea therapy decreases the in vitro adhesion of sickle erythrocytes to thrombospondin and laminin. Br J Haematol 2000;109(2):322327.

29. Odievre MH, Bony V, Benkerrou M, et al. Modulation of erythroid adhesion receptor expression by hydroxyurea in children with sickle cell disease. Haematologica 2008;93(4):502510.

30. Hines PC, Zen Q, Burney SN, et al. Novel epinephrine and cyclic AMP-mediated activation of BCAM/Lu-dependent sickle (SS) RBC adhesion. Blood 2003;101(8):3281-3287. 31. Murphy MM, Zayed MA, Evans A, et al. Role of Rap1 in promoting sickle red blood cell adhesion to laminin via BCAM/LU. Blood 2005;105(8):3322-3329.

32. Hillery CA, Du MC, Montgomery RR, Scott JP. Increased adhesion of erythrocytes to components of the extracellular matrix: isolation and characterization of a red blood cell lipid that binds thrombospondin and laminin. Blood 1996;87(11):4879-4886.

33. Gauthier E, Rahuel C, Wautier MP, et al. Protein kinase A-dependent phosphorylation of Lutheran/basal cell adhesion molecule glycoprotein regulates cell adhesion to laminin alpha5. $J$ Biol Chem 2005;280(34):30055-30062.

34. Daniels G. Lutheran Blood Group System. In: Daniels G, ed. Human Blood Groups. Oxford, UK: Blackwell Science; 1995:356-384.

35. Leclerc L, Galacteros F, Magne P, Bohn B, Poyart C. [Simple and rapid method for the fractionation of red blood cells in sickle cell anemia]. Nouv Rev Fr Hematol 1985;27(5):321-326. 
36. El Nemer W, Rahuel C, Colin Y, Gane P, Cartron JP, Le Van Kim C. Organization of the human LU gene and molecular basis of the $\mathrm{Lu}(\mathrm{a}) / \mathrm{Lu}(\mathrm{b})$ blood group polymorphism. Blood 1997;89(12):4608-4616.

37. Rahuel C, Le Van Kim C, Mattei MG, Cartron JP, Colin Y. A unique gene encodes spliceoforms of the B-cell adhesion molecule cell surface glycoprotein of epithelial cancer and of the Lutheran blood group glycoprotein. Blood 1996;88(5):1865-1872.

38. Kaul DK, Fabry ME, Nagel RL. The pathophysiology of vascular obstruction in the sickle syndromes. Blood reviews 1996;10(1):29-44.

39. Ballas SK, Smith ED. Red blood cell changes during the evolution of the sickle cell painful crisis. Blood 1992;79(8):2154-2163.

40. Cokic VP, Beleslin-Cokic BB, Tomic M, Stojilkovic SS, Noguchi CT, Schechter AN.

Hydroxyurea induces the eNOS-cGMP pathway in endothelial cells. Blood 2006;108(1):184-191.

41. Gladwin MT, Shelhamer JH, Ognibene FP, et al. Nitric oxide donor properties of hydroxyurea in patients with sickle cell disease. Br J Haematol 2002;116(2):436-444.

42. Huang J, Kim-Shapiro DB, King SB. Catalase-mediated nitric oxide formation from hydroxyurea. J Med Chem 2004;47(14):3495-3501.

43. King SB. Nitric oxide production from hydroxyurea. Free Radic Biol Med 2004;37(6):737-744.

44. Benkerrou M, Delarche C, Brahimi L, et al. Hydroxyurea corrects the dysregulated Lselectin expression and increased $\mathrm{H}_{2} \mathrm{O}_{2}$ production of polymorphonuclear neutrophils from patients with sickle cell anemia. Blood 2002;99(7):2297-2303.

45. Canalli AA, Franco-Penteado CF, Traina F, Saad ST, Costa FF, Conran N. Role for cAMP-protein kinase A signalling in augmented neutrophil adhesion and chemotaxis in sickle cell disease. Eur J Haematol 2007;79(4):330-337.

46. Lee SP, Cunningham ML, Hines PC, Joneckis CC, Orringer EP, Parise LV. Sickle cell adhesion to laminin: potential role for the alpha5 chain. Blood 1998;92(8):2951-2958.

47. Zen Q, Batchvarova M, Twyman CA, et al. B-CAM/LU expression and the role of B$\mathrm{CAM} / \mathrm{LU}$ activation in binding of low- and high-density red cells to laminin in sickle cell disease. Am J Hematol 2004;75(2):63-72.

48. An X, Gauthier E, Zhang X, et al. Adhesive activity of Lu glycoproteins is regulated by interaction with spectrin. Blood 2008;112(13):5212-5218.

49. Gauthier E, El Nemer W, Wautier MP, et al. Role of the interaction between Lu/BCAM and the spectrin-based membrane skeleton in the increased adhesion of hereditary spherocytosis red cells to laminin. Br J Haematol 2010;148(3):456-465.

50. Kroviarski Y, El Nemer W, Gane P, et al. Direct interaction between the Lu/B-CAM adhesion glycoproteins and erythroid spectrin. Br J Haematol 2004;126(2):255-264. 


\section{Figure Legends}

Figure 1. Fewer SS RBCs adhered to laminin during HU treatment. (A) Blood samples from 7 healthy controls, 28 untreated (UT) and 34 HU-treated patients (HU). Horizontal lines are medians. UT RBCs were more adherent than HU RBCs $\left(2\right.$ dyne $/ \mathrm{cm}^{2}, P=.007$; Mann-Whitney test). Note that exposure to HU led to less dispersion of HU group values as compared to the UT group $(P<.0001$; Fisher's exact test). (B) For the pre-post group, RBC adhesion was significantly lower after 6 months of $\mathrm{HU}(\mathrm{M} 6)$ than before $\left(2\right.$ dyne/cm ${ }^{2}, \mathrm{n}=13 ; P=.013$; Wilcoxon signed-rank test).

\section{Figure 2. HU-exposed SS RBC adhesion to laminin decreased while Lu/BCAM erythroid} expression increased. Lu/BCAM expression was measured by flow cytometry using anti-Lu monoclonal antibody F241. (A,B) SS RBC adhesion as a function of the percentage of RBCs from 12 untreated (UT) and 14 HU-treated patients expressing Lu/BCAM ( $\left.\mathrm{Lu} / \mathrm{BCAM}^{+}\right)(\mathrm{A})$ or of Lu/BCAM mean fluorescence intensity (MFI) (B); (C,D) Lu/BCAM expression level on the surface of RBCs from 19 UT and 19 HU-treated patients represented as the percentage of circulating RBCs expressing Lu/BCAM (C) and the latter's MFI (D); HU increased the percentage of Lu/BCAM-positive RBCs $(P<.0001)$ and Lu/BCAM MFI $(P<.0001$; MannWhitney test). Horizontal lines are medians. (E,F) Same as (C,D) for the 5 pre-post-group patients before (D0) and during HU treatment (D15, M2, M4 and >M6).

\section{Figure 3. Erythroid expression of Lu and Lu(v13) during HU treatment. Lu and Lu(v13)} were immunoprecipitated and revealed by Western blotting. (A) Typical result showing the presence of $\mathrm{Lu}(85 \mathrm{kDa})$ and $\mathrm{Lu}(\mathrm{v} 13)(78 \mathrm{kDa})$ before and during $\mathrm{HU}$ treatment. (B) Box and whiskers representing the $\mathrm{Lu} / \mathrm{Lu}(\mathrm{v} 13)$ ratio of 5 pre-post group patients during HU treatment. The 
internal horizontal line is the median, lower and upper box limits correspond to the $25^{\text {th }}$ and $75^{\text {th }}$ percentiles and the T-bars represent the range.

\section{Figure 4. Lu/BCAM phosphorylation (P), RBC adhesion and evolution of 3 blood}

parameters during HU treatment. (A) Typical results ( 1 of 5 experiments) obtained with prepost-group patient's SS RBCs showing the phosphorylation of the Lu-gp long isoform after RBC radiophospholabeling and immunoprecipitation of Lu/BCAM. The percentage of reticulocytes was determined by flow cytometry of each sample. Total immunoprecipitated Lu/BCAM proteins were quantified by Western blotting (WB). The P/WB ratio estimates the proportion of phosphorylated proteins. Vertical lines have been inserted to indicate repositioned gel lanes. (B) Box and whiskers representing Lu/BCAM phosphorylation in 5 patients before (D0) and during HU treatment (D15, M2 and >M6). The internal horizontal line is the median, lower and upper box limits correspond to the $25^{\text {th }}$ and $75^{\text {th }}$ percentiles and the T-bars represent the range. HU significantly decreased Lu/BCAM phosphorylation $(P=.005$; Friedman test) (AU: arbitrary units). (C) Lu/BCAM-phosphorylation change after 6 months of HU treatment for each of the 5 patients. (D) Evolution of RBC adhesion under treatment for the $5 \mathrm{HU}$-treated patients. (E) A linear-regression analysis between RBC adhesion and Lu/BCAM phosphorylation $\left(P=.0005, r^{2}=\right.$ 0.496). (F, G, H) Box and whiskers representing the evolution of reticulocyte percentages, $\mathrm{Hb}$ concentrations and $\mathrm{HbF}$ percentages, respectively.

\section{Figure 5. RBC adhesion to laminin at $0.4 \mathrm{dyne} / \mathrm{cm}^{2}$ and Lu/BCAM phosphorylation (P) after}

blood fractionation. (A) Adhesion of UT RBCs from whole blood (W), the reticulocyte-rich lowdensity fraction (LDF) and the pellet containing the mature RBC-rich fraction (PF). Horizontal lines are medians. More LDF cells adhered than those from $\mathrm{W}(P<.01)$ or the $\mathrm{PF}(P<.05$; 
Friedman test). (B) Typical results (1 of 5 experiments) showing the phosphorylation of the Lu-gp long isoform in $\mathrm{W}, \mathrm{LDF}$ and PF of an UT patient. The percentage of reticulocytes was determined by flow cytometry for each sample. Total immunoprecipitated Lu/BCAM proteins were quantified by Western blotting (WB). P/WB ratio estimates the proportion of phosphorylated

proteins. Vertical lines have been inserted to indicate repositioned gel lanes. (C) Linear regression between phosphorylation and reticulocyte percentage in UT-patients $\left(r^{2}=0.985, P<.0001, \mathrm{n}=5\right.$ patients, 3 samples for each patient: W, LDF and PF). (D) Lu/BCAM phosphorylation as a function of the reticulocyte percentage in $8 \mathrm{HU}$-treated patients $\left(r^{2}=0.03, P=.66, \mathrm{n}=8\right)$.

\section{Figure 6. Adhesion of K562-Lu cells to laminin and Lu-gp phosphorylation (P) during} exposure to HU. (A) Mean \pm s.e.m. numbers of K562-Lu cells adhering to laminin at 2 dyne/cm ${ }^{2}$ before (Control) and after 24 and 48 hours of exposure to $250 \mu \mathrm{M}$ of $\mathrm{HU}(\mathrm{n}=3)$. (B) Lu-gp phosphorylation of HU-treated K562-Lu cells (typical result); means \pm s.e.m. at 24 and 48 hours were $0.75 \pm 0.27$ and $0.27 \pm 0.1$, respectively $(n=3)$. HU exposure reduced K562-Lu adhesion to laminin and Lu-gp phosphorylation.

\section{Figure 7. Quantification of intracellular cAMP in RBCs and K562-Lu cells. Cyclic AMP} levels were measured using an enzyme immunoassay. (A) cAMP levels in 4 AA and 7 SS RBC samples. Each dot represents the measured cAMP value in $10^{8} \mathrm{RBC}$ from one patient. The horizontal lines are medians. (B) cAMP values measured in 7 patients during HU treatment at D0, D15, M2 and >M6. The decrease in cAMP levels was significant $(P=.002$; Friedman test $)$. (C) Decreased cAMP values measured in K562-Lu cells incubated with HU for 24 and 48 hours. 
Figure 1

A

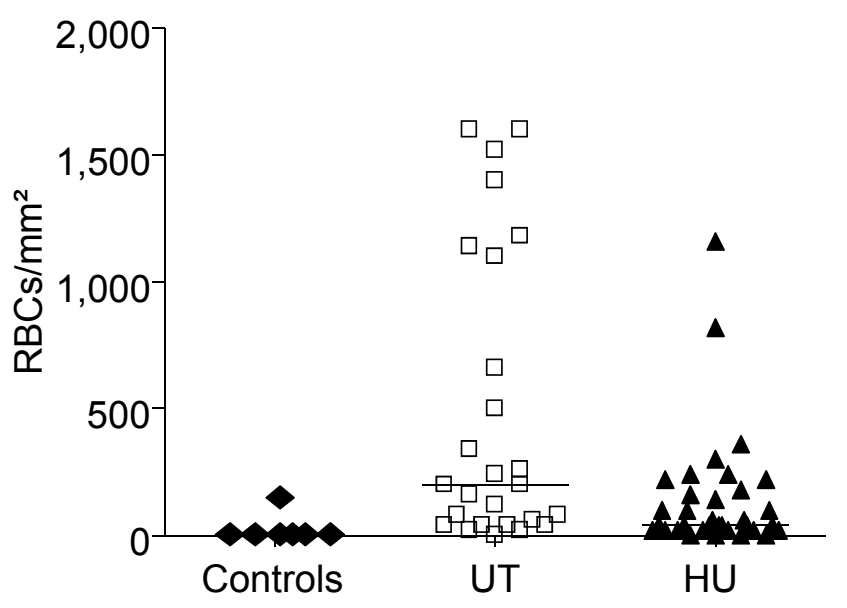

B

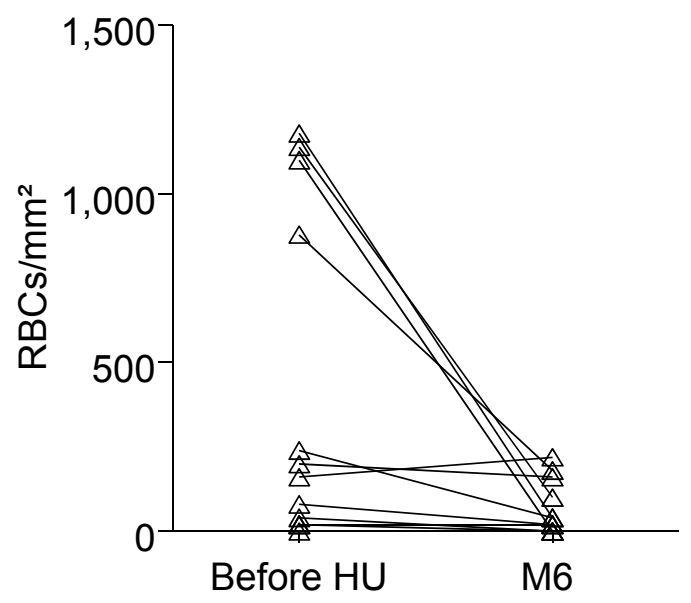


A
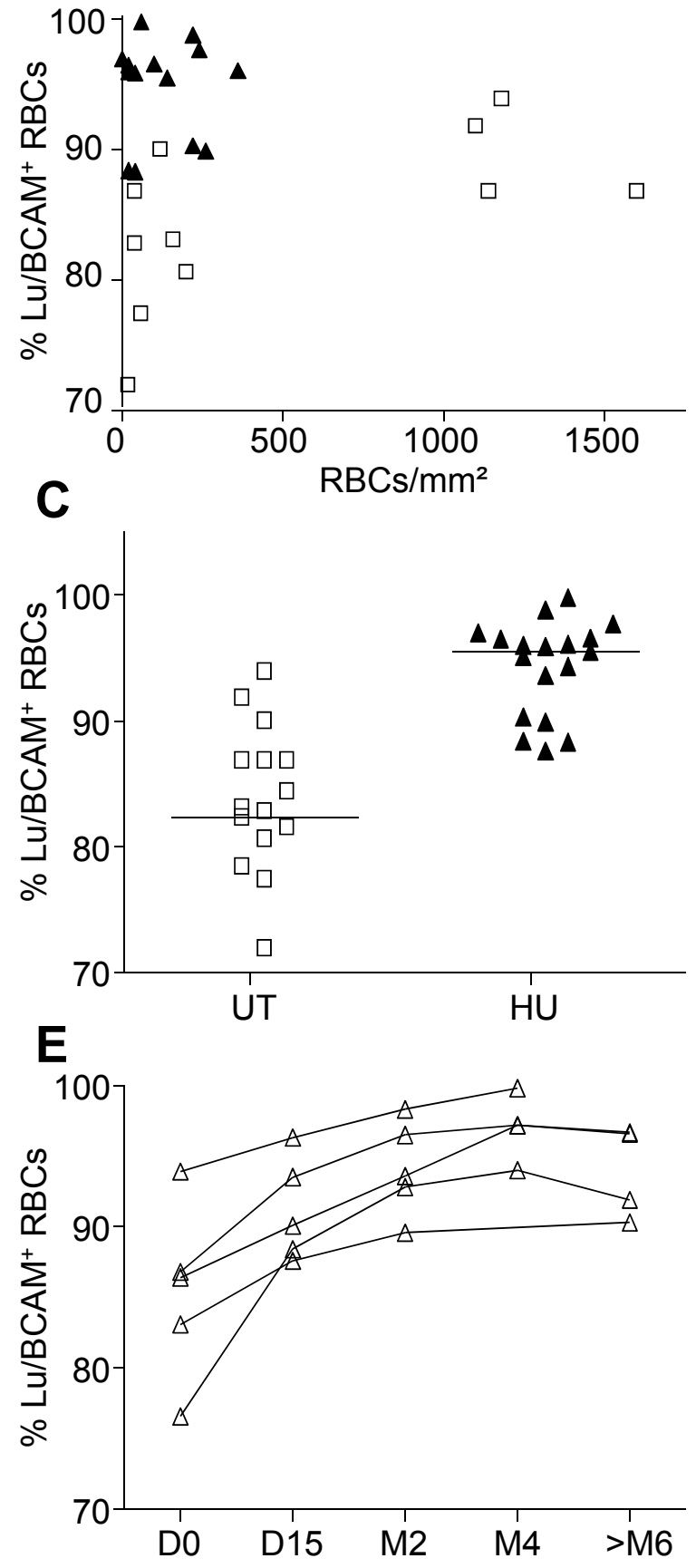

B
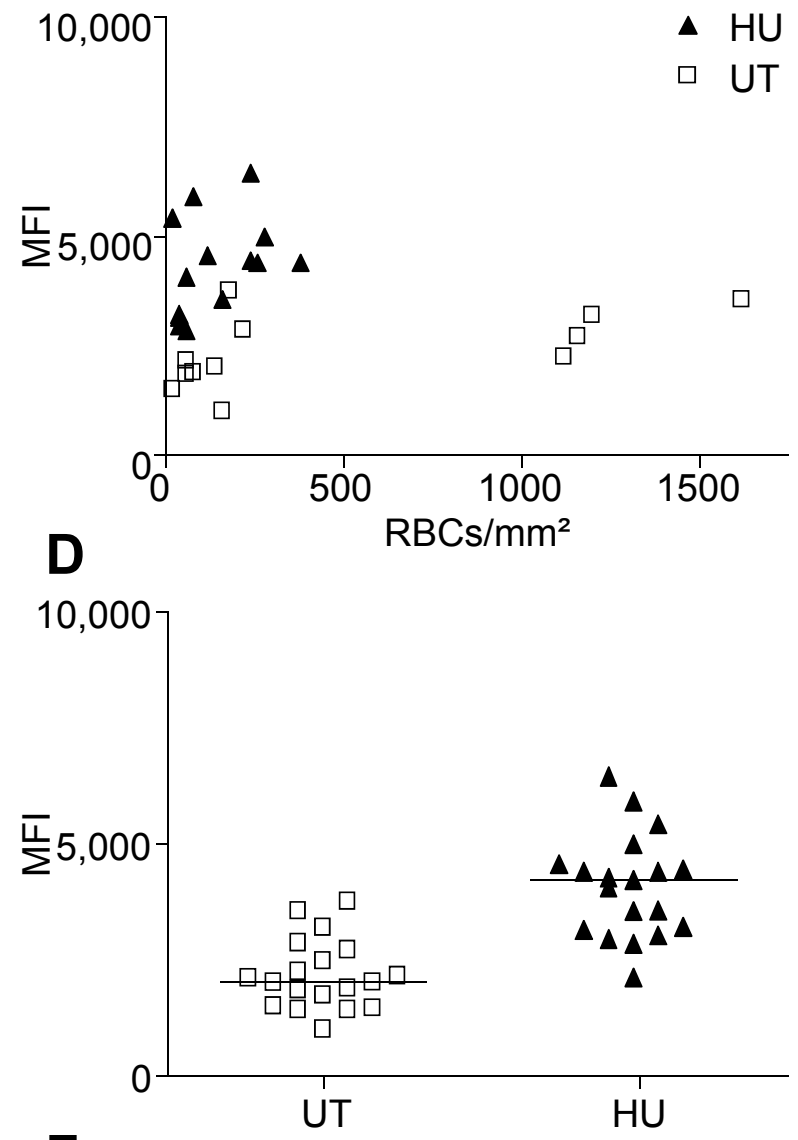

F

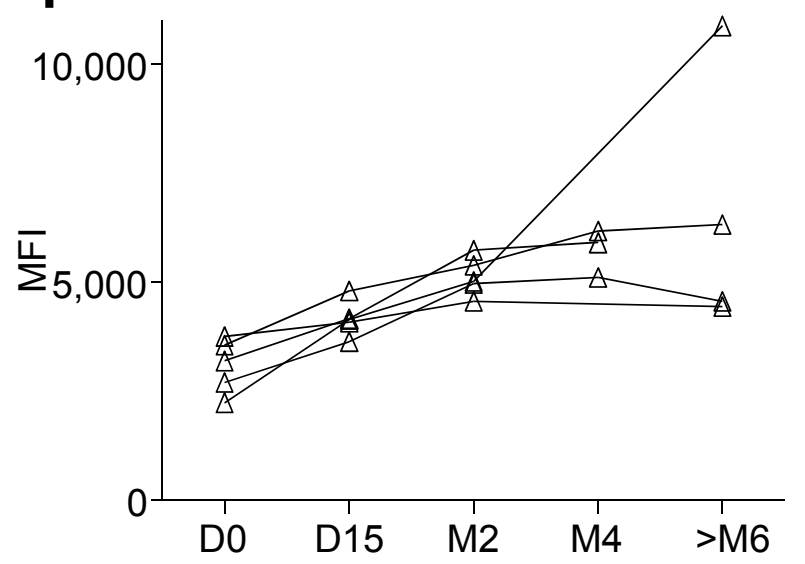


Figure 3

A

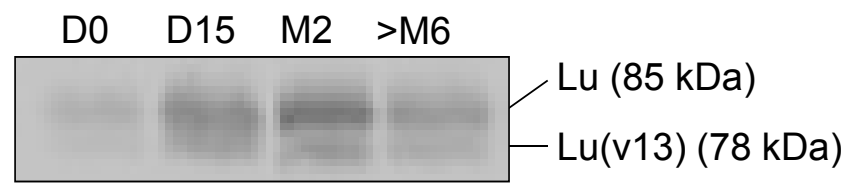

B

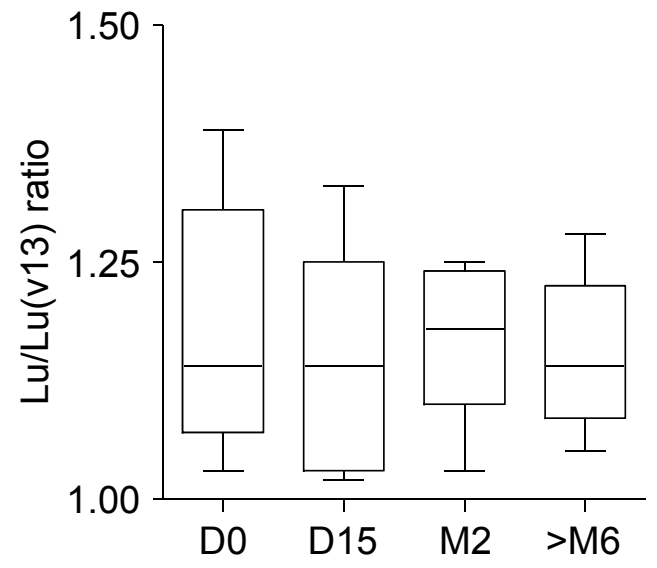


Figure 4

A
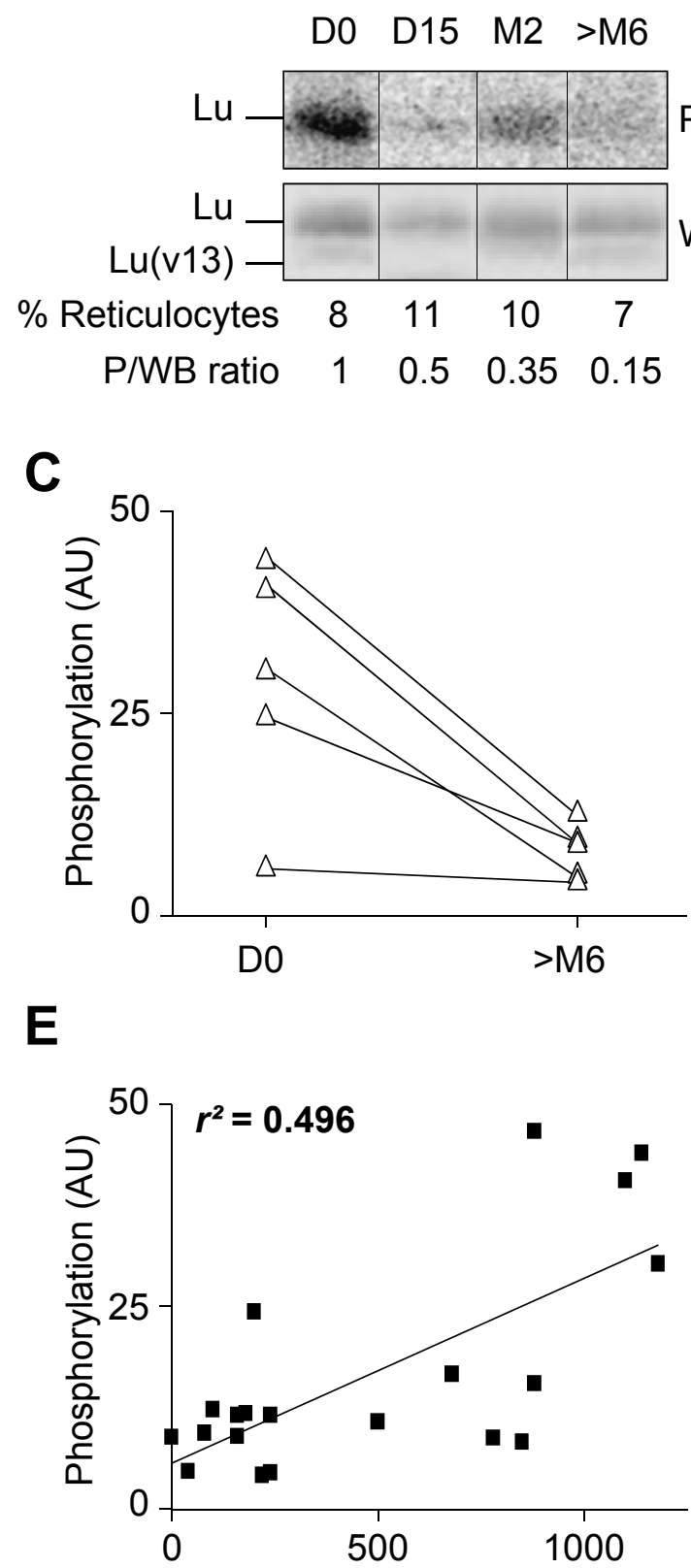

G

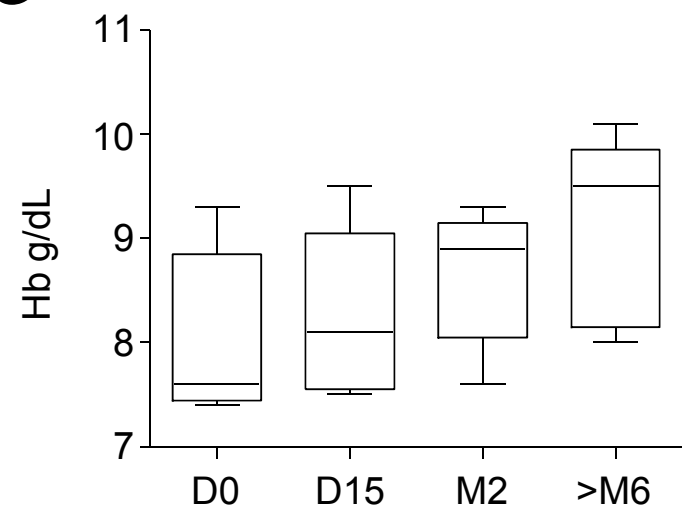

B

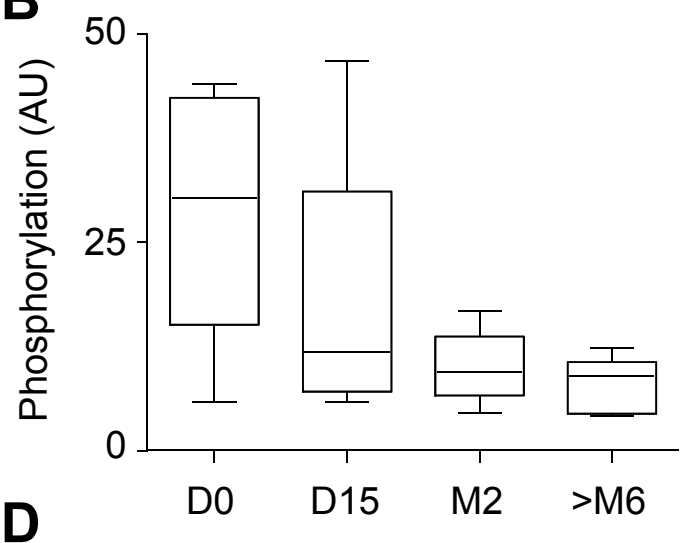

F
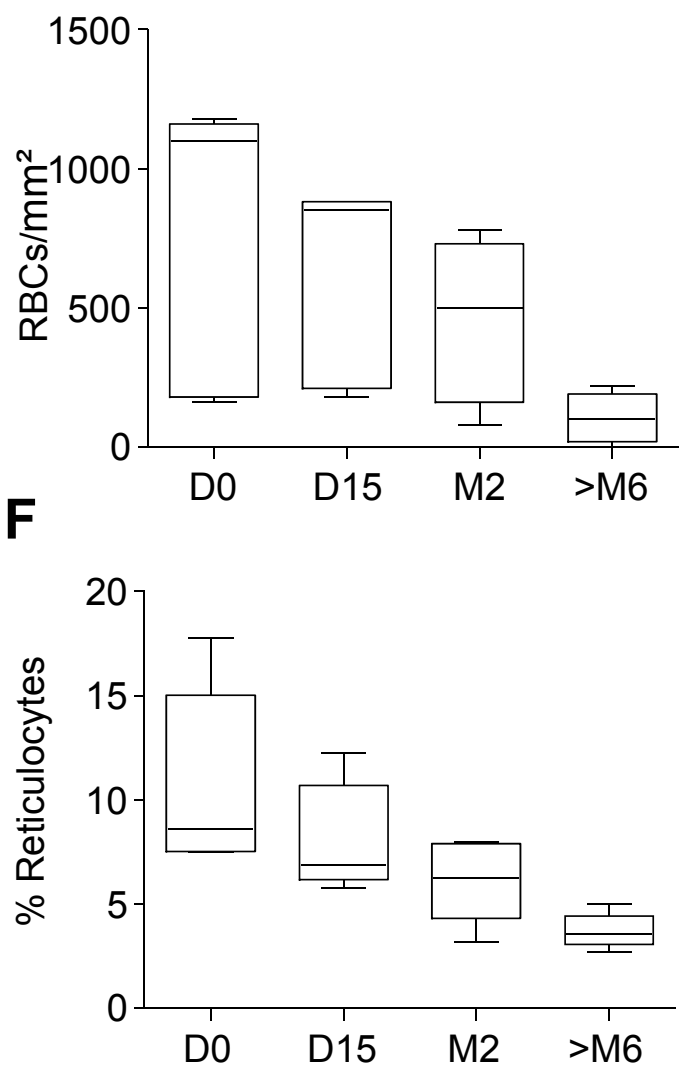

H

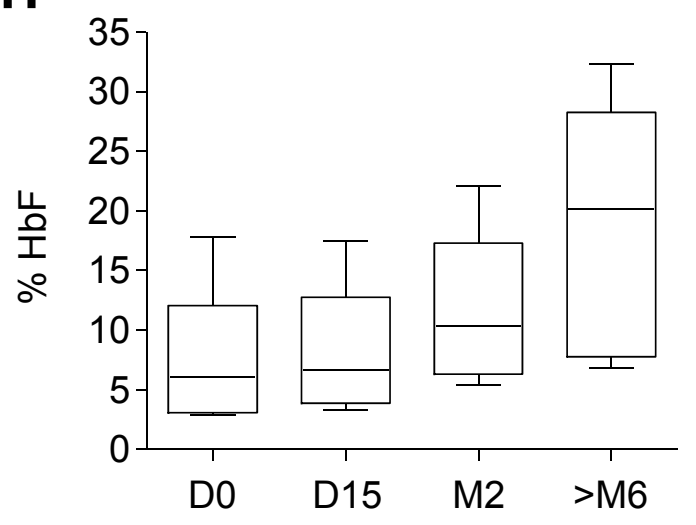


Figure 5

A

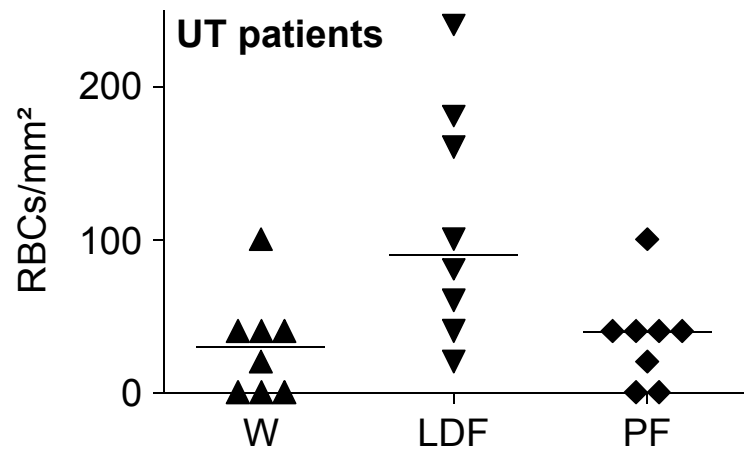

B
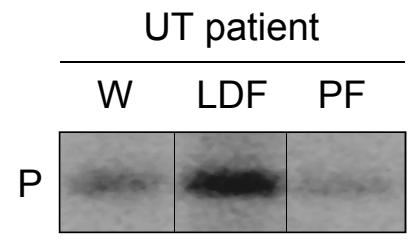

WB

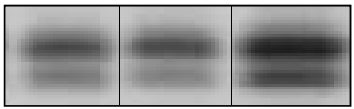

$\begin{array}{llll}\% \text { Reticulocytes } & 10.8 & 31 & 5.6\end{array}$

$\begin{array}{llll}\text { P/WB ratio } & 1 & 3 & 0.5\end{array}$

C
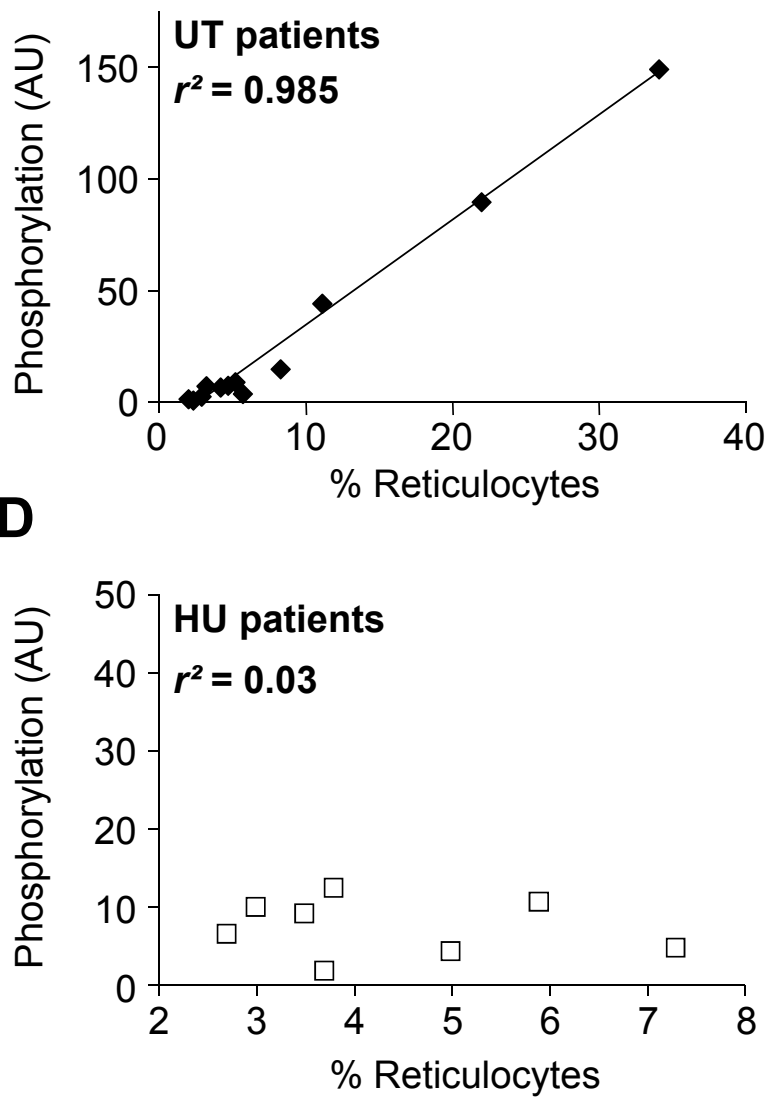
Figure 6
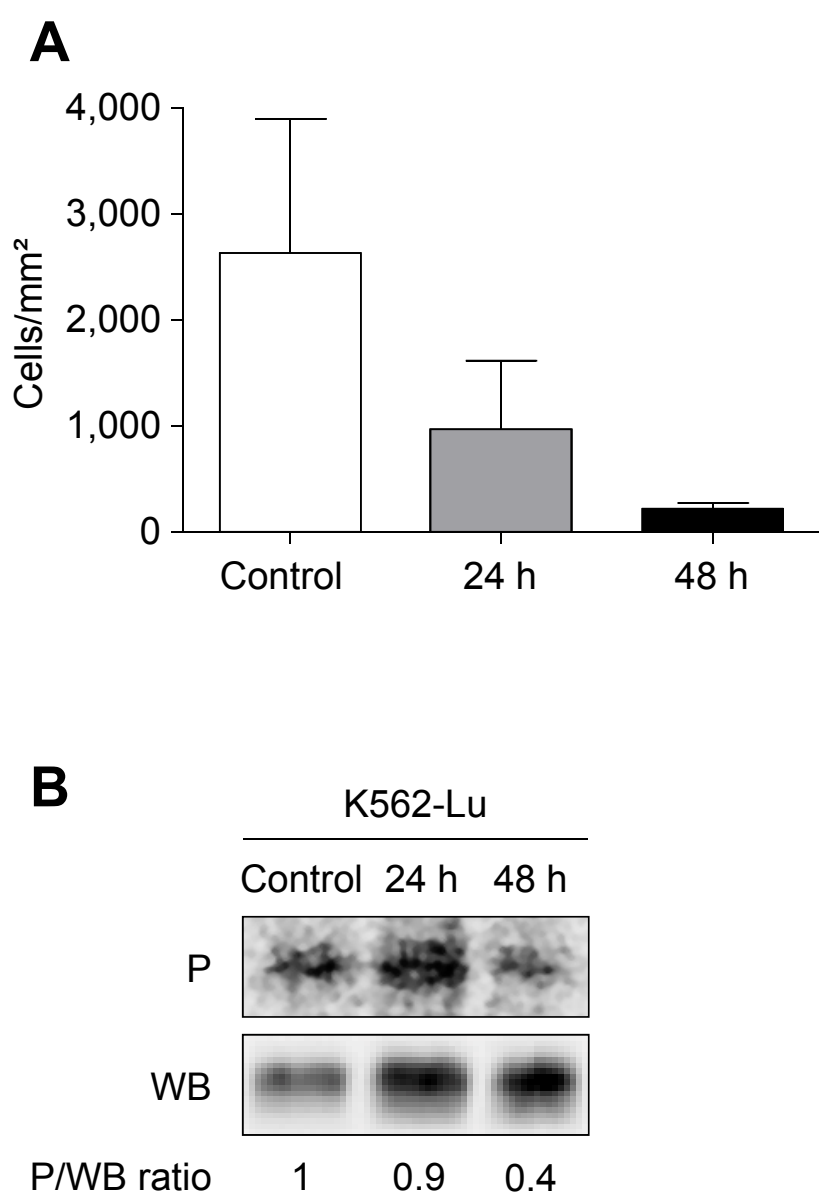
Figure 7

A

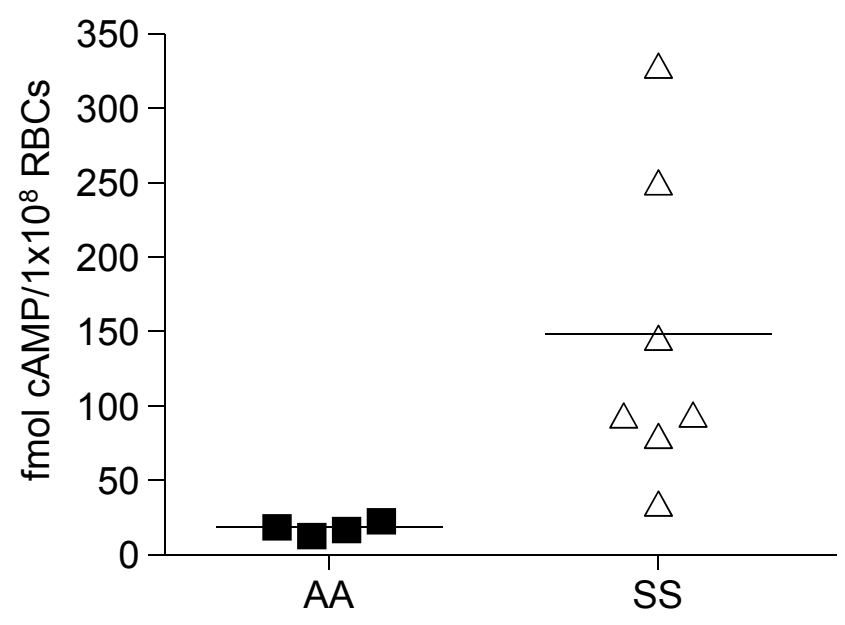

B

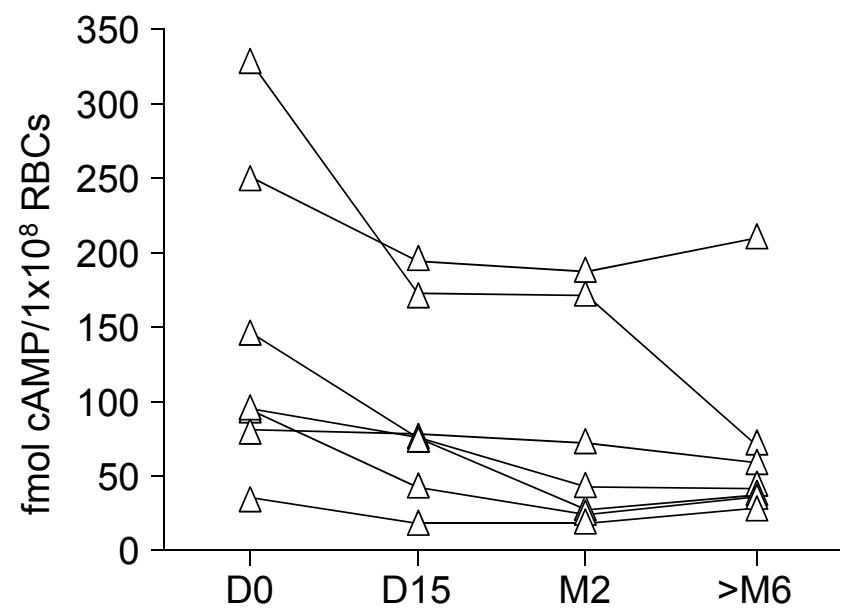

C

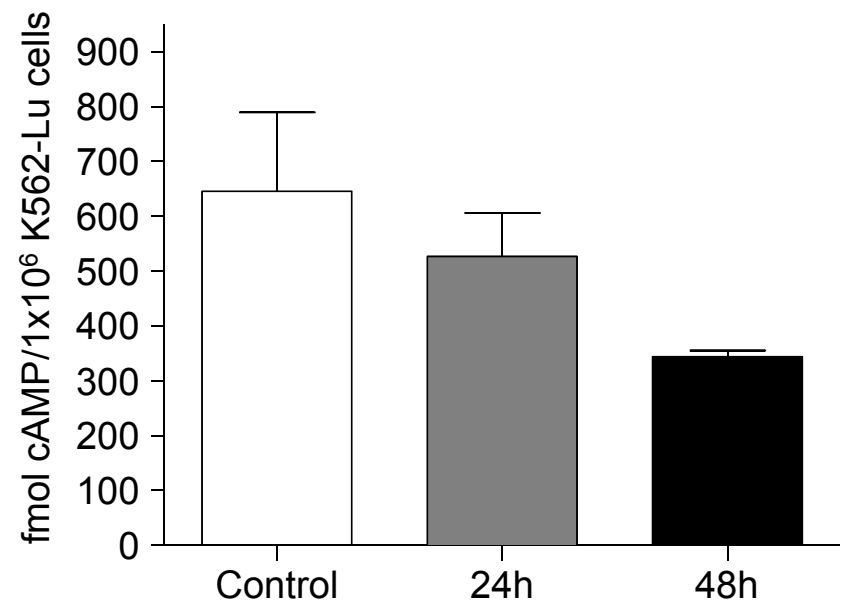

